\section{$\underset{\substack{\text { hommes } \\ \text { \& migrations }}}{ }$}

\section{Hommes \& migrations}

Revue française de référence sur les dynamiques

migratoires

$1295 \mid 2012$

Algérie - France : une communauté de destin

\title{
Cyril Pedrosa, Portugal
}

Dupuis, 2011, 264 pages, 35 euros

\section{Vincent Marie}

\section{(2) OpenEdition \\ 1 Journals}

Édition électronique

URL : http://journals.openedition.org/hommesmigrations/1106

DOI : 10.4000/hommesmigrations. 1106

ISSN : 2262-3353

Éditeur

Musée national de l'histoire de l'immigration

Édition imprimée

Date de publication : 1 janvier 2012

Pagination : 185

ISSN : 1142-852X

\section{Référence électronique}

Vincent Marie, «Cyril Pedrosa, Portugal », Hommes \& migrations [En ligne], 1295 | 2012, mis en ligne le 29 mai 2013, consulté le 22 septembre 2020. URL : http://journals.openedition.org/ hommesmigrations/1106; DOI : https://doi.org/10.4000/hommesmigrations.1106

Ce document a été généré automatiquement le 22 septembre 2020.

Tous droits réservés 


\title{
Cyril Pedrosa, Portugal
}

\author{
Dupuis, 2011, 264 pages, 35 euros
}

\section{Vincent Marie}

\section{RÉFÉRENCE}

Cyril Pedrosa, Portugal, Dupuis, 2011, 264 pages, 35 euros

1 Le point de départ de la bande dessinée Portugal de Cyril Pedrosa est autobiographique. Le récit retrace l'histoire de Simon, un dessinateur qui a perdu l'envie de dessiner. Comme Simon, alors qu'il avait l'impression que sa vie lui échappait, Cyril Pedrosa est invité au Portugal pour participer à un festival. Cette manifestation "présentait des BD que j'avais faites et dont je n'étais pas très content. Je n'aimais pas beaucoup mes livres. L'ironie, c'est que c'est grâce à eux que j'ai fait celui-là." À son arrivée, Simon redécouvre l'atmosphère $\mathrm{du}$ pays de son enfance et se trouve dans une grande confusion sentimentale: "J'étais fasciné et heureux. Un vrai crétin. Et je me demandais bien d'où venaient cette étrange colère puis cette douce mélancolie qui m'étaient tombées dessus sans crier gare en moins de 24 heures." À l'instar de son personnage de papier, lorsque l'auteur déambule dans les ruelles de Lisbonne, il vit une sorte "d'épiphanie lusophonique". Sur la planche, ce processus se traduit par la présence de bulles sur fond jaune dont la musicalité portugaise se mêle aux bruits de la rue. Il y a donc dans Portugal une sorte de "fado graphique" dont les contours nostalgiques privilégient souvent de grandes cases et une structure narrative originale. Le récit s'articule en effet autour de trois points de vue : celui de Simon (son double fictionnel), celui de son père Jean et celui de son grand-père Abel, immigré portugais qui a fui le régime de Salazar. Ainsi, chacune de ces histoires commence dans une station-service et présente une posture esthétique originale. Dans la première partie intitulée Pour Simon, les planches sont essentiellement monochromes avec parfois quelques petites touches de couleur. Le dessinateur a travaillé à partir d'un léger crayonné puis a utilisé le stylo Bic pour appliquer la technique du lavis avec une encre très épaisse diluée dans de l'eau. L'objectif était de mieux faire ressortir les ombres, les lumières et les intensités. Dans la 
deuxième partie, intitulée Selon Jean, le crayonné transparaît de façon encore plus nette et donne au récit un aspect pesant. Enfin, dans la dernière partie, Selon Abel, l'auteur s'est affranchi de toute contrainte graphique et son trait est plus libre.

2 Avec Portugal, Cyril Pedrosa réalise un véritable tour de force : celui de recréer non seulement un univers sonore et visuel original mais aussi celui de recomposer les fragments d'une histoire familiale dissolue, celle des Mucha(t) dont le nom porte d'ailleurs en lui les stigmates de l'exil puisque la lettre " $t$ " a vraisemblablement été ajoutée par un fonctionnaire peu rigoureux au moment où Abel (le grand-père) a émigré en France. Sous la plume et les pinceaux de Cyril Pedrosa, c'est une véritable “porte vers l'ailleurs" qui s'ouvre au lecteur et c'est dans l'esprit d'un exilé qu'il rédige dans l'épilogue de ce véritable chef-d'œuvre la dédicace suivante: "Pour Deosinda, Gracinda et Joaquin et tous ceux qui partent, parfois sans revenir..." 